\title{
Optimal Virtual Power Plant Management for Multiple Grid Support Services
}

DOI:

10.1109/TEC.2020.3044421

\section{Document Version}

Accepted author manuscript

Link to publication record in Manchester Research Explorer

\section{Citation for published version (APA):}

Bolzoni, A., Parisio, A., Todd, R., \& Forsyth, A. (2021). Optimal Virtual Power Plant Management for Multiple Grid Support Services. IEEE Transactions on Energy Conversion, 36(2), 1479-1490. [9292995].

https://doi.org/10.1109/TEC.2020.3044421

\section{Published in:}

IEEE Transactions on Energy Conversion

\section{Citing this paper}

Please note that where the full-text provided on Manchester Research Explorer is the Author Accepted Manuscript or Proof version this may differ from the final Published version. If citing, it is advised that you check and use the publisher's definitive version.

\section{General rights}

Copyright and moral rights for the publications made accessible in the Research Explorer are retained by the authors and/or other copyright owners and it is a condition of accessing publications that users recognise and abide by the legal requirements associated with these rights.

\section{Takedown policy}

If you believe that this document breaches copyright please refer to the University of Manchester's Takedown Procedures [http://man.ac.uk/04Y6Bo] or contact uml.scholarlycommunications@manchester.ac.uk providing relevant details, so we can investigate your claim.

\section{OPEN ACCESS}




\title{
Optimal Virtual Power Plant Management for Multiple Grid Support Services
}

\author{
A. Bolzoni, Member IEEE, A. Parisio, Senior Member IEEE, R. Todd, Senior Member IEEE, \\ A. J. Forsyth, Senior Member IEEE
}

\begin{abstract}
A hierarchical control architecture is proposed for the optimal day-ahead commitment of multiple grid support services within a virtual power plant (VPP). The day-ahead optimization considers pricing and cost data to determine the commitment schedule, and a robust Model Predictive Control (MPC) approach is included to minimize the unbalance fees during real-time operations. The multi-level control has been demonstrated experimentally using a hybrid test system, where the VPP is formed of a commercial $240 \mathrm{~kW}, 180 \mathrm{kWh}$ battery energy storage system (BESS), while the additional assets are modelled in a real-time digital simulator (RTDS). Two case studies are analyzed: the first assumes a purely-electrical VPP, with a single connection to the public network; the second involves a multi-energy approach, with the introduction of a gassupplied Combined Heat and Power unit (CHP). Both winter and summer price scenarios are tested. The results show the superiority of the multiple-service operation compared to providing a single grid support service. For example, the net revenue is increased by $30 \%$ (winter) and $7 \%$ (summer) when compared to just frequency regulation, and by $+99 \%$ (winter) and $30 \%$ (summer) when compared to only energy arbitrage.
\end{abstract}

Index Terms-Model Predictive Control, Multiple Service Provision, Virtual Power Plants, Power System Dynamics.

\section{NOMENCLATURE}

Time indexes and MPC parameters

$H, h \quad$ total prediction horizon and its index

$\Delta T, k \quad$ optimizations time step and its index

Battery Energy Storage System (BESS) parameters $i=1 \ldots N^{s t} \quad$ identification index for BESS storage units $P_{i}^{e a}, P_{i}^{f r \pm} \quad$ BESS energy-arbitrage / regulation power $\overline{P_{i}}, P_{i} \quad \max , \min$ BESS storage power limits ${\overline{P_{i}}}^{f r}, P_{i}^{f r}$ $\eta_{i}^{c h}, \overline{\eta_{i}^{d i s}}$ $\mathrm{SoC}_{i}, E_{i}$ over, under-frequency maximum provision $\mathrm{SoC}_{i}^{+}, \mathrm{SoC}_{i}^{-}$upper, lower bounds of uncertain storage $\mathrm{SoC}$ $\overline{S o C_{i}}, \underline{S_{o} C_{i}} \quad$ BESS max, min state of change levels

Reversible Thermal Storage (TS)

$P^{t s}, \overline{P_{t s}}, \underline{P}_{t s} \quad$ thermal-storage power and its limits

Financial support was provided by the UK Engineering and Physical Sciences Research Council (EPSRC) under the MANIFEST project (EP/N032888/1), and by Innovate UK under the project Q-PLUS Intelligent Building energy management utilizing energy storage (133463).

Authors are with the Department of Electrical and Electronic Engineering at The University of Manchester, M13 9PL, Manchester, UK.

alberto.bolzoni@manchester.ac.uk; alessandra.parisio@manchester.ac.uk; Andrew.Forsyth@manchester.ac.uk

Dedicated to the memory of our late colleague, Dr Rebecca Todd.
$S o C_{t s}, E_{t s} \quad$ thermal storage state of charge / rated energy

$\overline{S o C}_{t s}, \underline{S o C}_{t s}$ thermal storage max / min state of change $\eta_{t s}^{c h}, \eta_{t s}^{\text {dis }} \quad$ thermal storage conversion efficiencies

Building thermal control, photovoltaic and CHP unit $n=1 \ldots N^{t z}$ index for thermal zones in the building $P_{n}^{e l}, \dot{Q}_{n} \quad$ heat pump electrical absorption / injected heat $\vartheta_{n},\left[\vartheta_{n}, \overline{\vartheta_{n}}\right]$ thermal zone temperature and comfort limits $C_{n}^{t h}, \overline{G_{n}^{t h}} \quad$ thermal-zone capacitance, conductance $p_{n}, s_{n} \quad$ occupancy and irradiance sensitivity factors $\mathrm{O}_{n}, \mathrm{Ir} \quad$ thermal-zone occupancy and global irradiance $P^{p v}, \gamma^{p v} \quad$ photovoltaic power and production factor $P^{c h p}, \dot{Q}_{\text {tot }}^{c h p} \quad$ CHP power and total heat

$\dot{Q}_{n}^{c h p}, \eta^{P}, \eta^{Q} \quad$ CHP thermal zone heat and conversion factors $\dot{m}^{\text {gas }}, h^{\text {gas }} \quad$ CHP gas mass flow and specific heat

Global VPP profiles and cost functions

$P_{v p p}^{E A}, P_{v p p}^{F R \pm} \quad$ VPP energy-arbitrage / frequency regulation $C_{M K}, C_{G A S} \quad$ electrical energy / gas supply total costs $C_{A}, C_{\Omega} \quad$ BESS ageing and regulation provision costs $C_{E U}, C_{G U}$ $\lambda^{E A}, \lambda^{F R}$ $\lambda^{G A S}, \lambda^{u n b}$ $\lambda_{i}^{A 1}, \lambda_{i}^{A 2}, \lambda_{i}^{\Omega}$ electrical / gas unbalance market cost energy-arbitrage and regulation price profiles gas supply and unbalance fees cost profiles battery-ageing and regulation cost coefficients

\section{INTRODUCTION}

$\mathrm{L}^{\mathrm{s}}$ OW carbon technologies are increasingly deployed in

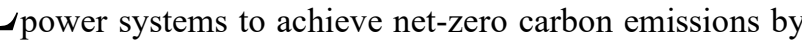
2050; these include distributed energy sources, storage systems and controllable loads, and are often grouped to form a virtual power plant (VPP) [1]. The diversified nature of the VPP assets allow frequency regulation services to be provided along with energy arbitrage, to maximize revenues.

Among the different VPP energy management control techniques, Model Predictive Control (MPC) is recognized as a promising option for the energy management applications and it has been adopted for energy-price arbitrage. In [2], a VPP consisting of electrochemical storage devices, PV systems and diesel gen-sets is coordinated by a centralized MPC algorithm to perform energy-price arbitrage while connected to a public power network. A similar approach is developed in [3], including the building thermal management and with a distributed (rather than centralized) scheme. In [4] the optimal control principle is extended to include non-linear battery ageing mechanisms; however, the optimization is again only focused on the energy-price arbitrage. The authors in [5] considered the frequency regulation scenario but it excludes energy-price arbitrage. These publications [2]-[5] demonstrated the effectiveness of the management schemes 
for single-market operations. However, the limitation to a single service prevents the full exploitation of the optimizations algorithm's capabilities. Furthermore, these approaches assume idealized off-line conditions rather than real-time operations [6]-[7]. Therefore, the development of a holistic management architecture able to maximize the VPP revenues by coordinating multiple stacked services is one of the main contributions of this paper, which is not considered in any of the aforementioned approaches.

Only recently some publications analyzed the possibility of increasing the revenue of a VPP system through coordinated bidding strategies in different markets. A first attempt to combine frequency regulation services with energy arbitrage is presented in [8], however the two operations are presented as mutually exclusive, no mathematical modeling of the service stacking is proposed, and the optimal condition is assessed empirically rather than analytically. This means that a global optimum may not be reached as the model simply chooses an empirical best-option between finite alternatives, rather than searching the entire set of feasible profiles.

A few papers have described optimality-based service stacking, but none considered a real-time implementation on a grid-scale system. The authors in [9] analyze a simple system consisting of one Battery Energy Storage (BESS) and a wind generator. Extensions are described in [10] to multiple BESS systems, in [11] to the battery degradation phenomena, and in [12] to market prices sensitivity. However, the absence of real-time unbalance fees management into the algorithm design and the lack of a grid scale experimental testing represent the major limitations of [9]-[12], especially due to the impossibility to assess how the unpredictable intra-day network frequency behavior is managed by the VPP control. This degree of uncertainty is not taken into account in [9][12] and leads to a deviation of the real profiles from the ideal day-ahead ones. Furthermore, none of these approaches is tested under a multi-energy scenario (electricity + gas).

To combine the multiple time-scales involved in the VPP management (from the day-ahead scale of the market, to the almost-instantaneous frequency regulation), a hierarchical multi-layer control architecture is proposed and demonstrated experimentally in this paper. Typically, such hierarchical control is used for optimal power dispatch and loss minimization in islanded micro-grids [13]-[14] but has rarely been tested for the provision of stacked services.

The goal is to design a complete optimizations framework able to model the frequency regulation and the energy arbitrage stacking within the same mathematical formulation in a VPP. This includes detailed characteristics for the storage units (e.g. non-ideal efficiency, ageing phenomena) and the impact of the uncertain power sign associated with the frequency regulation. Compared to previous work, this paper provides three key contributions.

Modeling: the proposed approach includes key elements often neglected in the literature, like BESS non-ideal conversion efficiency and ageing, whose impact could significantly affect the VPP performance; a multi-energy scenario is also considered. In addition, the paper proposes a novel storage model that accounts for the provision of multiple services (energy arbitrage and frequency regulation).

$>$ Control design: differently from the existing literature, the proposed architecture includes not only the day-ahead markets, but also the unbalance fees impact. The control accounts for the current network standards and multiple time scales, and it is robust against real-time unbalance fees due to the unpredictable grid frequency evolution. These aspects have not been found in any other publications, to the best of authors' knowledge.

$>$ Validation and assessment: the proposed control framework is tested on a unique real-time grid scale set-up under real operating conditions. The testbed consists of a hardware BESS interfaced to a network simulator for highfidelity validation. The experimental testing of an extended VPP during real-time stacking operations has not been analyzed in the literature, to the best of authors' knowledge. The considered VPP architecture includes a diversified fleet of flexibility assets (BESS, renewable energy sources, building thermal demand, thermal storage and $\mathrm{CHP}$ ).

In Section III the hierarchical architecture is introduced, while in Section IV the proposed mathematical modeling of the service stacking is analyzed. The model is exploited within a robust MPC-based approach to reduce the unbalance fees volatility in Section V. A detailed representation of the experimental set-up is provided in Section VI. Results for two different case studies are discussed in Section VII-VIII.

\section{HIERARCHICAL ARCHITECTURE}

An overview of the three-layer hierarchical VPP control architecture is shown in Fig. 1, where each layer is distinguished by a different time-scale. Five assets are considered but many others could be easily incorporated:

- an intermittent photovoltaic (PV) generator;

- the thermal management of a building, which has flexibility in its energy consumption;

- a reversible thermal storage (TS) system used only for energy arbitrage due to its slow internal dynamics;

- three BESS units with different power / energy ratings, able to provide energy arbitrage and frequency regulation service with a response time below one second;

- a Combined Heat and Power (CHP) unit, which allows the algorithm performance to be tested with multiple energy vectors (electrical grid + gas supply).

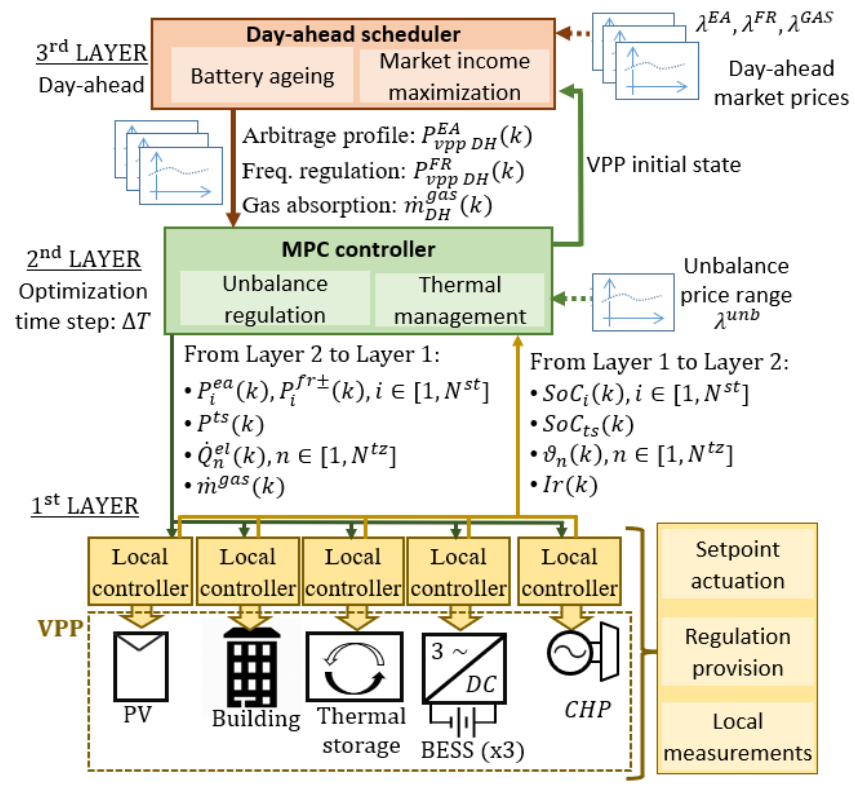

Fig. 1: Proposed hierarchical control architecture for the VPP 


\section{A. Description of Layers}

Day-ahead ( $D H)$ scheduler ( $3^{\text {rd }}$ layer): the slowest layer solves an optimization problem over a one-day horizon to maximize the net revenue determined by the stacking of energy arbitrage and frequency regulation (thereby emulating a simplified bidding mechanism of the VPP on the market). This includes the determination of the global VPP contribution to energy arbitrage and frequency regulation, and the allocation of these services to the internal assets.

Intra-day MPC controller ( $2^{\text {nd }}$ layer): this intermediate control layer acquires as inputs the expected energy arbitrage power profile $P_{v p p D H}^{E A}$, together with the frequency regulation limit $P_{v p p D H}^{F R}$ for each asset in the VPP from the day-ahead scheduler, and performs the MPC-based on-line management of the assets. The control objectives are to guarantee the fulfilment of the profiles scheduled by the $3^{\text {rd }}$ layer and the provision of the agreed frequency regulation capability at the lowest technical cost for the VPP (including asset ageing and unbalance fees), while managing the stored heat and guaranteeing the thermal comfort for building occupants. This is achieved by calculating the optimal reference values and control parameters for the local controllers of the $1^{\text {st }}$ layer. The MPC controller updates the control signals to the units every $\Delta T=30 \mathrm{~min}$ based on the current measured system condition through the feedback mechanism embedded into the MPC scheme. Furthermore, a robust approach [15] is adopted to mitigate the uncertainty related to the unbalance fee costs. Alternative robust frameworks are available in the literature, e.g., [16], however they are not suitable for the problem addressed in this study because they require a convex problem formulation. Furthermore, in [16] the optimization is performed over closed-loop control policies, which would be computationally significantly demanding.

$>$ Local controllers ( $1^{\text {st }}$ layer): Each asset is equipped with internal local regulators, which guarantee the local fast dynamics convergence to the reference state trajectory, typically within some millisecond [17]. The reference signals are updated by the $2^{\text {nd }}$ layer at every sampling period $\Delta T$. The local controllers also enable the continuous provision of the frequency regulation: the latest requirements for the converter-oriented units performing fast frequency services imply the provision of the regulation power proportional to the allocated margins (assigned by the $3^{\text {rd }}$ layer and updated by the $2^{\text {nd }}$ layer) within one second from the frequency event e.g. for the UK [18] and Italian [19] cases. The fast service execution is only manageable at the local level ( $1^{\text {st }}$ layer $)$, while the $2^{\text {nd }}$ layer determines the positive (over-frequency) and negative (under-frequency) regulation limits coherently with the asset energy state and its physical constraints. The local controllers feature and its interaction with the intra-day $2^{\text {nd }}$ layer is highlighted in the next subsection.

\section{B. Electrical / thermal storage local control: $1^{\text {st }}$ layer}

Fig. 2-a shows the local regulation layer for the BESS systems, based on the grid-following architecture [20] which controls the power flow at the converter interface. The total power set-point is the sum of $P_{i}^{e a}$, which is due to the energy arbitrage, and a frequency-dependent term associated with the regulation support defined by the allocated positive / negative regulation margins $P_{i}^{f r \pm}$. The MPC ( $2^{\text {nd }}$ layer $)$ updates $P_{i}^{e a}$ and $P_{i}^{f r \pm}$ every optimization step $\Delta T$, determining the storage average exchanged energy and its dependence on the frequency transients; the BESS system feeds back its State of Charge to the MPC. The regulation term follows the simple piecewise-linear droop-based scheme of the traditional primary frequency support (Fig. 2-a), using the measured frequency as input: the dead-band and maximum frequency excursion are set by the grid standards, and the frequency measurement uses the method in [21]. The response time of these systems is within the maximum allowed value of one second [18]-[19].

The thermal storage (TS) unit is modelled in a similar way, but the frequency regulation limits are set to zero since the TS is unable to provide a rapid response due to the slow time constants involved in the thermal conversion process.

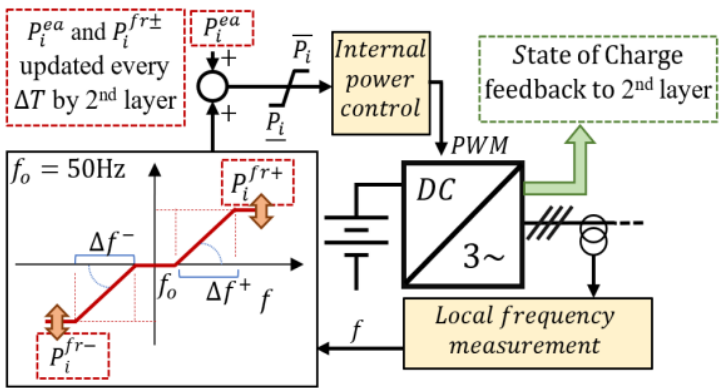

(a) Battery storage

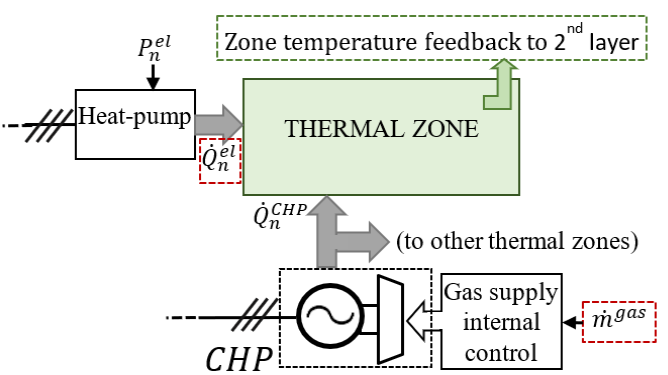

(b) Building thermal control and CHP

Fig. 2: Local control schemes for (a) the battery storage and (b) building thermal control and CHP.

\section{Building thermal control and CHP: $1^{\text {st }}$ layer regulators}

The building thermal management is carried out through heat pumps (one for each thermal zone TZ, $n=1 \ldots N^{t z}$ ) and a CHP unit. Fig. 2-b shows the local control layers for these assets. The local controllers for the heat-pumps manage the heat flux $\dot{Q}_{n}^{e l}$ in the thermal zones, leading to the electrical absorption $P_{n}^{e l}$ from the network. The local controller for the CHP manages the time-varying gas supply $\dot{m}^{\text {gas }}$ following the set-point defined by the MPC model. Part of the gassupplied power is converted into an electrical injection, while the heat is conveyed to the building ( $\dot{Q}_{n}^{C H P}$ in Fig. 2-b). The measured temperature $\vartheta_{n}$ in each thermal zone is fed back to the MPC in the $2^{\text {nd }}$ layer. The MPC sets the optimal inputs $\dot{Q}_{n}^{e l}$ and $\dot{m}^{g a s}$ (for the heat-pumps and CHP, respectively) based on the thermal model of the zones in Section IV.B.

\section{PV model}

The PV system is modelled as a time-varying power source $P^{p v}$ proportional to the irradiance $I r$ through a coefficient $\gamma^{p v}$ which defines the PV rating. 


$$
P^{p v}=\gamma^{p v} I r
$$

Since day-ahead irradiance forecasters [22] have been shown to have good accuracy, the actual irradiance profile $I r$ is assumed known in the $3^{\text {rd }}$ and $2^{\text {nd }}$ layers (aside for a normally-distributed error $\sigma_{p}$ ). The PV contributes to the VPP energy arbitrage profile, as an internal independent power source. Nevertheless, unlike the BESS units, it does not contribute to the fast frequency regulation, so there is no power-frequency droop associated with the PV injection.

\section{VPP ASSETS MODELING (2ND AND 3RD LAYERS)}

This section describes the modeling of the VPP assets as used in the optimization problems of $2^{\text {nd }}$ and the $3^{\text {rd }}$ layers.

\section{A. BESS and thermal storage devices}

The BESS units which provide frequency regulation and/or energy arbitrage must be modelled in the MPC formulation to retain the effects of both services on the asset power allocation and state-of-charge (SoC). This is challenging due to the impossibility to predict the polarity of the frequency deviation and the sign of the associated energy flow.

Consider the dynamic model of the $i$-th BESS $(i=$ $1 \ldots N^{s t}$ ) when it is providing price-arbitrage and instantaneous frequency regulation. If the energy of the storage unit at time step $k$ is $S o C_{i}(k)$, then the SoC at the next time step, $\operatorname{SoC}_{i}(k+1)$, depends on the energy arbitrage power $P_{i}^{e a}(k)$ and the frequency regulation margins $P_{i}^{f r \pm}(k)$ according to the scheme in Fig. 2-a. The impact of $P_{i}^{e a}$ on the SoC (assuming a positive $P_{i}^{e a}$ for charging operation) is:

$$
\begin{gathered}
\operatorname{SoC}_{i}(k+1)=\operatorname{SoC}_{i}(k)+\frac{\eta_{i} \Delta T}{E_{i}} P_{i}^{e a}(k) \\
\eta_{i}=\left\{\begin{array}{lc}
\eta_{i}^{c h} & \text { if } P_{i}^{e a}(k) \geq 0 \\
1 / \eta_{i}^{\text {dis }} & \text { else }
\end{array}\right.
\end{gathered}
$$

where $\eta_{i}$ is the conversion efficiency, $\Delta T$ is the time step and $E_{i}$ is the BESS's nominal energy.

The frequency regulation power is dependent on the unpredictable frequency deviation, therefore the change in the $\mathrm{SoC}$ while providing frequency regulation is unknown. However, the MPC needs to guarantee a degree of robustness against SoC saturation as this would inhibit the operability of the BESS device. To address this, two additional variables $S_{o} C_{i}^{+}$and $S_{o} C_{i}^{-}$are used to model the time-varying upper and lower bounds of the SoC for the known energy arbitrage contribution $P_{i}^{e a}$ and unknown frequency regulation, which is limited by $P_{i}^{f r \pm}$ and actually dependent on the measured frequency. The upper limit $\mathrm{SoC}_{i}^{+}$(4) assume that the asset will be asked to deliver continuously its allocated overfrequency margin $P_{i}^{f r+}(k)$ during the step from $\mathrm{k}$ to $\mathrm{k}+1$, while the opposite (permanent under-frequency) is assumed for $\mathrm{SoC}_{i}^{-}$(5). Fig. 3.a sketches the SoC evolution with $\mathrm{SoC}_{i}^{ \pm}$.

$$
\begin{aligned}
& \operatorname{SoC}_{i}^{+}(k+1)=S o C_{i}(k+1)+\frac{\eta_{i}^{\mathrm{ch}} \Delta T}{E_{i}} P_{i}^{f r+}(k) \\
& \operatorname{SoC}_{i}^{-}(k+1)=S o C_{i}(k+1)+\frac{\Delta T}{\eta_{i}^{\text {dis }} E_{i}} P_{i}^{f r-}(k)
\end{aligned}
$$

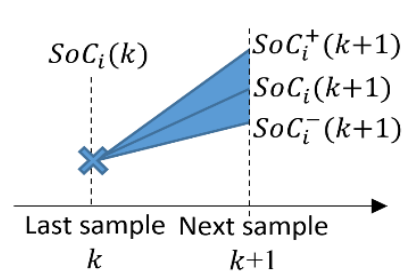

(a)

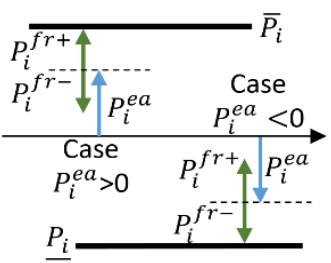

(b)

Fig. 3: SoC evolution (a), and power allocation between the services (b).

The definitions (4)-(5) represent a compromise between the service robustness and the profitability of the VPP itself. Specifically, an energy margin is allocated to provide the full regulation capability $P_{i}^{f r \pm}$ for the entire next step $\Delta T$. The proposed approach guarantees strong robustness of the committed regulation even under the most adverse network conditions. To guarantee that the maximum and minimum battery energy constraints are met, the inequalities (6) are applied to the SoC upper and lower bounds in the optimization problem, Fig. 3.a.

$$
\operatorname{SoC}_{i}^{+}(k+1) \leq \overline{\operatorname{SoC}_{i}} \text { and } \operatorname{SoC}_{i}^{-}(k+1) \geq \underline{\operatorname{SoC}_{i}}
$$

In addition, the power allocation between the frequency regulation limits $P_{i}^{f r+}$ and $P_{i}^{f r-}$, and arbitrage $P_{i}^{e a}$ must be compliant with the converter power ratings, Fig. 3.b. This is done by imposing the constraints (7)-(8) on the decision variables $P_{i}^{e a}$ and $P_{i}^{f r \pm}$. Equation (8) provides an adaptive constraint-tightening approach to achieve robustness while compensating for uncertainty in the frequency dynamics.

$$
\begin{gathered}
\underline{P_{i}} \leq P_{i}^{e a}(k)+P_{i}^{f r \pm}(k) \leq \overline{P_{i}} \\
\underline{P_{i}-} P_{i}^{f r-}(k) \leq P_{i}^{e a}(k) \leq \overline{P_{i}}-P_{i}^{f r+}(k)
\end{gathered}
$$

Depending on the physical characteristics of each asset and on the desired contribution to the service provision, the frequency regulation limits $P_{i}^{f r \pm}(k)$ can be determined by the optimization problem with the constraints:

$$
\begin{gathered}
P_{i}^{f r+}(k) \in\left[0, \overline{P_{i}^{f r}}\right] \geq 0 \text { where } \overline{P_{i}^{f r}} \leq \overline{P_{i}} \\
P_{i}^{f r-}(k) \in\left[P_{i}^{f r}, 0\right] \leq 0 \text { where } \underline{P_{i}^{f r}} \geq \underline{P_{i}}
\end{gathered}
$$

A similar modeling approach can be used for the reversible thermal storage (TS) device, provided that the frequency regulation limits $P_{t s}^{f r}, \bar{P}_{t s}^{f r}$ are set to zero to account for the TS being unable to provide an instantaneous response.

Equations (4)-(9) describe the complete storage system dynamics used in the optimization problem for each BESS, as a function of the decision variables $S_{o} C_{i}^{ \pm}, P^{e a}, P_{i}^{f r \pm}$. The logical condition (3) needs to be modelled through additional binary variables, as reported in the Appendix, where the BESS and TS dynamics are expressed through mixed integer linear equalities and inequalities. Hence, the resulting optimization problems in the $2^{\text {nd }}$ and $3^{\text {rd }}$ control layers show a Mixed Integer Linear Programming (MILP) form, which can be efficiently solved by a Branch-and-Bounds algorithm.

\section{B. Building thermal dynamics and CHP}

The temperature control of the building thermal zones is managed through two energy vectors: first the electricallysupplied heat-pumps (one for each thermal zone TZ, $n=$ $1 \ldots N^{t z}$ ); and second the heat from the gas-supplied CHP. 
Each heat-pump $\left(n=1 \ldots N^{t z}\right)$ absorbs a power $P_{n}^{e l}(k)$ determined by the polarity and magnitude of the heat $\dot{Q}_{n}^{e l}$ exchanged with the TZ, expressed by (10). The boundaries $\dot{Q}_{n}^{e l} \in\left[\underline{\dot{Q}_{n}^{e l}} ; \overline{\dot{Q}_{n}^{e l}}\right]$ identify the positive (heating) and negative (cooling) thermal flows.

$$
\left\{\begin{array}{c}
\dot{Q}_{n}^{e l}(k) \geq 0 \leftrightarrow P_{n}^{e l}(k)=\dot{Q}_{n}^{e l}(k) / C O P_{n}^{H} \geq 0 \\
\dot{Q}_{n}^{e l}(k)<0 \leftrightarrow P_{n}^{e l}(k)=-\dot{Q}_{n}^{e l}(k) / C O P_{n}^{C}>0
\end{array}\right.
$$

$\operatorname{COP}_{n}^{H}$ and $\operatorname{COP}_{n}^{C}$ are the coefficients of performance during heating and cooling operations.

The CHP unit is modelled through (11)-(13):

$$
\begin{gathered}
P^{c h p}=\eta^{P} h^{g a s} \dot{m}^{\text {gas }}(k) \\
\dot{Q}_{t o t}^{c h p}(k)=\eta^{Q} h^{g a s} \dot{m}^{g a s}(k) \\
\dot{Q}_{n}^{c h p}(k)=\dot{Q}_{\text {tot }}^{c h p}(k) / N^{t z}
\end{gathered}
$$

The MPC $2^{\text {nd }}$ layer defines the optimal gas consumption $\dot{m}^{\text {gas }} \in\left[0, \overline{\dot{m}}^{\text {gas }}\right]$, which leads to the injected electrical power $P^{c h p}$ and total heat $\dot{Q}_{\text {tot }}^{c h p}$ (11)-(12), Fig. 2-b; $h^{\text {gas }}$ is the gas lower specific heat $\left(h^{g a s}=10.6 \mathrm{kWh} / \mathrm{m}^{3}\right)$, while $\eta^{P} /$ $\eta^{Q}$ are the conversion efficiencies. The CHP heat is equally distributed between the thermal zones, according to (13).

The thermal dynamics of each zone are obtained by the discrete-time system (14), as in [23].

$$
\begin{aligned}
& \vartheta_{n}(k+1)=\vartheta_{n}(k)+\frac{\Delta T}{C_{n}^{t h}}\left[\dot{Q}_{n}^{e l}(k)+\dot{Q}_{n}^{c h p}(k)+\right. \\
& \left.+\left(\vartheta_{a}(k)-\vartheta_{n}(k)\right) G_{n}^{t h}+s_{n} I r(k)+p_{n} O_{n}(k)\right] \\
& \underline{\vartheta_{n}} \leq \vartheta_{n}(k) \leq \overline{\vartheta_{n}}, \forall k \in[1, H], \forall n \in\left[1, N^{t z}\right]
\end{aligned}
$$

where $\vartheta_{n}(k) / \vartheta_{a}(k)$ are the thermal zone / ambient temperatures, $C_{n}^{t h}[\mathrm{~J} / \mathrm{K}]$ and $G_{n n}^{t h}[\mathrm{~W} / \mathrm{K}]$ are the thermal capacitance and conductance parameters, while $\operatorname{Ir}(k)$ and $O_{n}(k)$ represent the solar irradiance and thermal-zone occupancy. The indoor temperatures vary within a predefined range set by (15), ensuring the occupiers comfort regardless of the time-varying external (e.g. solar irradiance) and internal (e.g. occupancy level) conditions.

\section{Grid power balance and total regulation provision}

The assets are mutually and optimally coordinated by the hierarchical control to maximize the net revenue, whilst respecting the operational limits of the VPP. Considering the generic VPP in Fig. 4, which includes all the flexibility assets, the total power flow for Energy Arbitrage EA operations $P_{v p p}^{E A}$ is given by (16).

$P_{v p p}^{E A}(k)=\sum_{i=1}^{N^{s t}} P_{i}^{e a}(k)+\sum_{n=1}^{N^{t z}} P_{n}^{e l}(k)+P^{t s}(k)-P^{p v}(k)-P^{c h p}(k)$

The only units entitled to provide the frequency regulation FR are the battery storages; thus, the total regulation limits are expressed by (17), where a global symmetrical frequency service is considered through the second equality sign.

$$
P_{v p p}^{F R}(k)=\sum_{i=1}^{N^{s t}} P_{i}^{f r+}(k)=-\sum_{i=1}^{N^{s t}} P_{i}^{f r-}(k)
$$

Importantly the global symmetrical modeling of the regulation margins in (17) does not imply a symmetric regulation for each single unit. Furthermore, each assets may provide different contributions to the two services (EA and FR): all the technologies play a role in the energy arbitrage (16), but BESS units only can guarantee a reliable provision of the fast frequency regulation (17) within the time set by the grid standards [18]-[19].

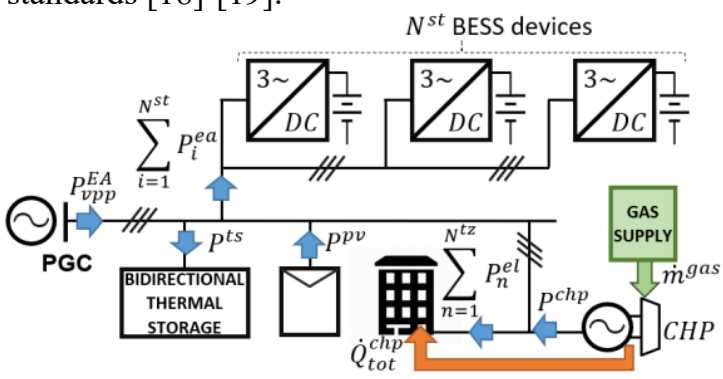

Fig. 4: VPP layout

The $3^{\text {rd }}$ and $2^{\text {nd }}$ layers act on day-ahead and intra-day time scales respectively, and the optimization approaches in each of these layers are described in the following sections. To distinguish the different layers, the subscript DH will be used to indicate day-ahead variables ( $3^{\text {rd }}$ layer), as opposed to intra-day variables ( $2^{\text {nd }}$ layer $)$

\section{VPP OPTIMIZATION-BASED CONTROL}

\section{A. Market operations ( $3^{\text {rd }}$ layer)}

The $3^{\text {rd }}$ layer scheduler defines the global day-ahead (DH) profiles for the energy-arbitrage $P_{v p p D H}^{E A}(k)$ and frequency regulation $P_{v p p D H}^{F R}(k)$ commitment, to maximize the net revenue of the VPP. Assuming prices $\lambda_{k}^{E A}$ for arbitrage and $\lambda_{k}^{F R}$ for frequency regulation, then the cost function for the $3^{\text {rd }}$ layer calculates the revenue from the energy and regulation markets $C_{M K},(18)$, plus the cost of battery ageing $C_{A},(19) . C_{A}$ includes the degradation per cycle and the accelerated wearout induced by high-power flows as modelled in [24].

$$
\begin{gathered}
C_{M K}=\sum_{k=1}^{H}\left\{\lambda_{k}^{E A} P_{v p p D H}^{E A}(k)-\lambda_{k}^{F R} P_{v p p D H}^{F R}(k)\right\} \Delta T \\
C_{\mathrm{A}}=\sum_{i=1}^{N^{s t}}\left\{\sum_{k=1}^{H} \frac{\lambda_{i}^{\mathrm{A} 1} \Delta T}{2 E_{i}}\left|P_{i D H}^{e a}(k)\right|+\frac{\lambda_{i}^{\mathrm{A} 2}}{\bar{P}_{i}} \max _{k \in[1 ; H]}\left|P_{i D H}^{e a}(k)\right|\right\} \\
C_{\Omega}=\sum_{i=1}^{N^{s t}} \sum_{k=1}^{H} \lambda_{i}^{\Omega}\left\{P_{i D H}^{f r+}(k)+\left|P_{i D H}^{f r-}(k)\right|\right\} \Delta T
\end{gathered}
$$

Equation (20) takes into account the cost of the service provision by each BESS, to prioritize the allocation of the regulation reserve to the units with the lower marginal regulation cost $\lambda_{i}^{\Omega}$. In addition, the VPP sustains the gassupply costs $C_{G A S}$, proportional to the parameter $\lambda_{k}^{G A S}$ :

$$
C_{G A S}=\sum_{k=1}^{H}\left\{\lambda_{k}^{G A S} \dot{m}_{D H}^{g a s}(k)\right\} \Delta T
$$

During the DH market session ( $3^{\text {rd }}$ layer), a single optimization based on (22) is carried out, which defines the arbitrage and frequency regulation limit profiles $P_{v p p D H}^{E A}$ and $P_{v p p D H}^{F R}$ for the next day.

$$
\min _{x_{D H}}\left(C_{M K}+C_{A}+C_{\Omega}+C_{G A S}\right)
$$


subject to

-the storage model (4)-(9), expressed in MILP form though additional decision variables as in the Appendix;

-the building thermal model (10)-(15);

-the VPP aggregation, expressed by (16)-(17), where

$$
\begin{gathered}
x_{D H}=\left\{P_{v p p D H}^{E A}, P_{v p p D H}^{F R}, P_{i D H}^{e a}, P_{i D H}^{f r t}, S o C_{i D H}^{ \pm},\right. \\
\left.P_{D H}^{t s}, S o C_{D H}^{t s}, \dot{Q}_{n D H}^{e l}, P_{n D H}^{e l}, \dot{Q}_{n D H}^{c h p}, \dot{m}_{D H}^{g a s}, \vartheta_{n D H}\right\}
\end{gathered}
$$

These day-ahead profiles, $P_{v p p D H}^{E A}, P_{v p p D H}^{F R}$ and $\dot{m}_{D H}^{g a s}$ from the market session are sent from the $3^{\text {rd }}$ layer to the MPC controller ( $2^{\text {nd }}$ layer), which monitors the adherence of the VPP to the profiles, and reallocates resource, if required, to fulfil the commitment.

\section{B. Minimizing unbalance costs ( $2^{\text {nd }}$ layer)}

The MPC manages the dynamics of the VPP assets and can reallocate assets to cope with the uncertainty caused by the intra-day operations. The objective is to minimize the costs of deviating from the day-ahead scheduled $P_{v p p D H}^{E A}(k)$ (unbalance fees) whenever the disturbances or uncertainties prevent fulfilment of the pre-defined profile. This is modelled through the $\operatorname{cost} C_{E U}(23)$, which is the difference between the actual absorption $P_{v p p}^{E A}$ and the scheduled day-ahead profile $P_{v p p D H}^{E A}$ obtained from the day-ahead scheduler (22). Different pricing models for the unbalance fees could easily be implemented but are out of the scope of this paper.

$$
C_{E U}=\sum_{k=1}^{H} \lambda_{k}^{u n b} \max \left\{P_{v p p}^{E A}(k)-P_{v p p D H}^{E A}(k), 0\right\} \Delta T
$$

Furthermore, the mismatch between the actual $\left(\dot{m}^{\text {gas }}\right)$ and the day-ahead ( $\dot{m}_{D H}^{g a s}$ ) gas absorption is expressed is (24), leading to the intra-day cost function for the $2^{\text {nd }}$ layer in $(25)$.

$$
\begin{gathered}
C_{G U}=\sum_{k=1}^{H} \lambda_{k}^{G A S} \max \left\{\dot{m}^{g a s}(k)-\dot{m}_{D H}^{g a s}(k), 0\right\} \Delta T \\
\min _{x}\left(C_{E U}+C_{G U}\right)
\end{gathered}
$$

subject to

- the storage model (4)-(9), expressed in MILP form though additional decision variables as in the Appendix; -the building thermal model (10)-(15);

-the VPP aggregation, expressed by (16)-(17), where

$$
\begin{gathered}
x=\left\{P_{v p p}^{E A}, P_{v p p}^{F R}, P_{i}^{e a}, P_{i}^{f r \pm}, S o C_{i}^{ \pm},\right. \\
\left.P^{t s}, S_{o} C^{t s}, \dot{Q}_{n}^{e l}, P_{n}^{e l}, \dot{Q}_{n}^{c h p}, \dot{m}^{g a s}, \vartheta_{n D H}\right\} .
\end{gathered}
$$

Differently from the $3^{\text {rd }}$ layer optimization, the intra-day $2^{\text {nd }}$ layer defines the set-points $\left(P_{i}^{e a}, P^{t s}, \dot{Q}_{n}^{e l}, \dot{m}^{g a s}\right)$ to minimise the unbalance fees (25). The day-ahead profiles $P_{v p p D H}^{E A}$ and $\dot{m}_{D H}^{g a s}$ from the $3^{\text {rd }}$ layer day-ahead scheduler are the inputs of the MPC problem in the $2^{\text {nd }}$ layer. The MPC also guarantees that the intra-day frequency regulation limits $P_{i}^{f r \pm}$ are compliant with the day-ahead profile $P_{v p p D H}^{F R \pm}$

The inherent feedback of the MPC guarantees a recalculation of the optimal local trajectory at each iteration step $k$, to minimise the unbalance cost (25). This is important since the unbalance-price factor $\lambda_{k}^{u n b}$ is not known in advance, as it is a measure of the unforeseen balancing costs sustained by the transmission system operator (TSO) during each period. A robust approach is essential to reduce the risk associated with the volatility of $\lambda_{k}^{u n b}$, and to guarantee limited sensitivity of the solution to the specific price conditions. As in [15], the unbalance price is modelled as a bounded random variable $\tilde{\lambda}_{k}^{u n b}$ taking values in $\left[\lambda_{k}^{u n b} ; \lambda_{k}^{u n b}+d_{k}^{u n b}\right]$, where $d_{k}^{u n b} \geq 0$ is the maximum price variation for each period, based on past observations. The goal for the robust approach is to increase the resilience of the VPP to unbalance in the network $\left(P_{v p p}^{E A}(k)-P_{v p p D H}^{E A}(k)>0\right)$ whenever the price is higher than expected. Therefore, the cost function in (25) is modified to include the worst case:

$$
\min _{\mathrm{x}}\left\{C_{E U}+C_{G U}+\max _{\substack{S \subseteq H \\|S|<\Gamma}} \sum_{j \in S} d_{j}^{u n b}\left[P_{v p p}^{E A}(j)-P_{v p p D H}^{E A}(j)\right] \Delta T\right\}
$$

The term in (26) proportional to the maximum deviation $d^{u n b}$ takes into account the risk of buying energy at a higherthan-expected price (worst-case condition robustness). The user-defined parameter $\Gamma$ sets the number of time steps within the horizon $\mathrm{H}$ in which the solution should avoid the overprice $d^{u n b}$. The robustness term in (26) in MILP becomes:

$$
\begin{aligned}
& \min _{\mathrm{x}}\left\{\max _{S \subseteq H,|S|<\Gamma} \sum_{j \in S} d_{j}^{u n b}\left[P_{v p p}^{E A}(j)-P_{v p p D H}^{E A}(j)\right] \Delta T\right\}= \\
& =\min _{\mathrm{x}}\left\{\sum_{j=1}^{H} u_{j}+\Gamma z_{0}\right\} \Delta T \\
& \text { s.t. } u_{j} \geq 0, z_{0} \geq 0 \quad \forall j \in[1, H] \\
& z_{0}+u_{j} \geq d_{j}^{u n b}\left[P_{v p p}^{E A}(j)-P_{v p p D H}^{E A}(j)\right], \forall j \in[1, H]
\end{aligned}
$$

\section{SET-UP DESCRIPTION AND CASE STUDY DEFINITION}

\section{A. Real-time hybrid set-up description}

The hybrid experimental set-up in Fig. 5 is used to demonstrate the effectiveness of the proposed hierarchical VPP control in a real-time high-fidelity environment, with a hardware BESS device. The RTDS is used to model in realtime the two other BESS units, the TS, the PV and the building. The parameters of the battery storage systems are typical for low-voltage grid-connected applications [8]-[25]. A real-time LAN communication between the RTDS and the MATLAB environment enables the MPC problem and the day-ahead scheduling ( $2^{\text {nd }}$ and $3^{\text {rd }}$ layers) to be solved on-line though the Branch-and-Bounds IBM CPLEX solver. The dSpace board in Fig. 5 implements the BESS local control described in Fig. 2-a (frequency measurement and linear power-droop regulation). It also acts as a communication gateway between the LAN and the converter PLC.

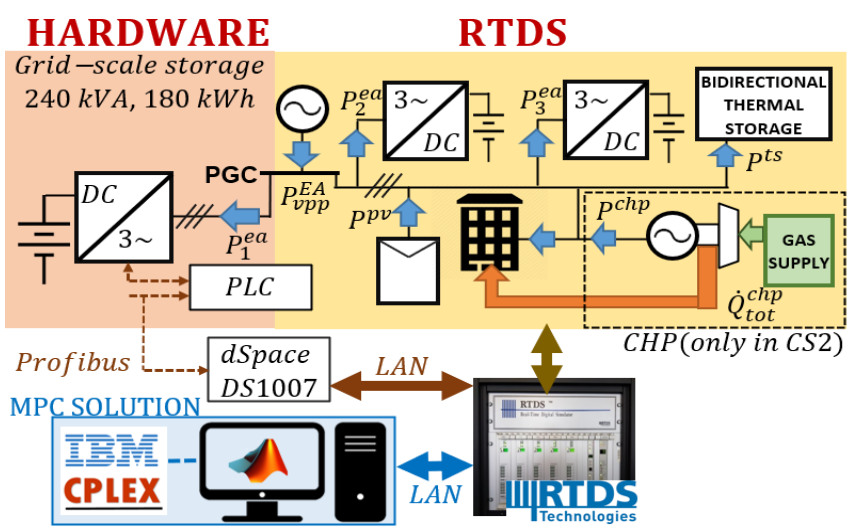

Fig. 5: Hybrid experimental set-up structure 
TABle I: STORAGE AND BUILdING PARAMETERS

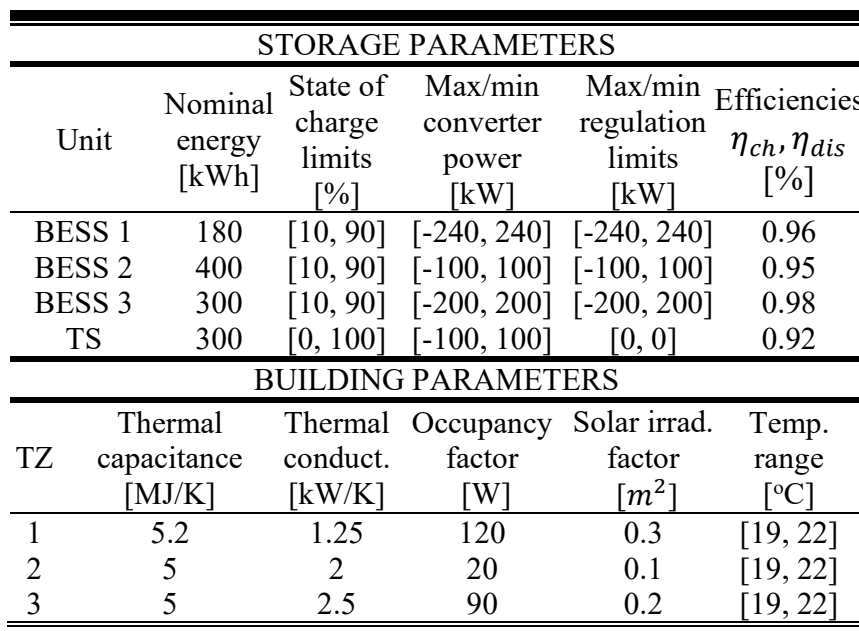

TABLE II: Cost PARAMETERS \& REG. SERVICE

\begin{tabular}{ccc}
\hline \hline \multicolumn{3}{c}{ BATTERIES } \\
\hline Unit & Ageing coeff. $\lambda_{i}^{\mathrm{A} 1}, \lambda_{i}^{A 2}$ & Freq. reg. cost $\lambda^{\Omega}$ \\
\hline BESS 1 & $0.03 £ /$ cycle, $6 \mathrm{e}-3 £ / \mathrm{kW}$ & $1 \mathrm{e}-4 £ / \mathrm{kW}$ \\
BESS 2 & $0.02 £$ cycle, $2.5 \mathrm{e}-3 £ / \mathrm{kW}$ & $4 \mathrm{e}-4 £ / \mathrm{kW}$ \\
BESS 3 & $0.04 £ /$ cycle, $4 \mathrm{e}-3 £ / \mathrm{kW}$ & $1 \mathrm{e}-4 £ / \mathrm{kW}$ \\
\hline \multicolumn{3}{c}{ MARKET PROFILES } \\
\hline Quantity (UK data) & Value or Profile & Reference \\
\hline$\lambda^{E A}, \lambda^{\text {unb }}$ & Fig. 6 & {$[26]-[27]$} \\
$\lambda^{F R}$ & $5 £ /$ MW for each hour & - \\
$\lambda^{G A S}$ & $0.3 £ / \mathrm{m}^{3}$ & - \\
\hline \multicolumn{3}{c}{ FREQUENCY REGULATION SERVICE } \\
\hline Max provision & Frequency dead-band & Reg. range \\
delay 1 s & $49.95-50.05 \mathrm{~Hz}$ & $49.85-50.15 \mathrm{~Hz}$ \\
\hline \hline
\end{tabular}

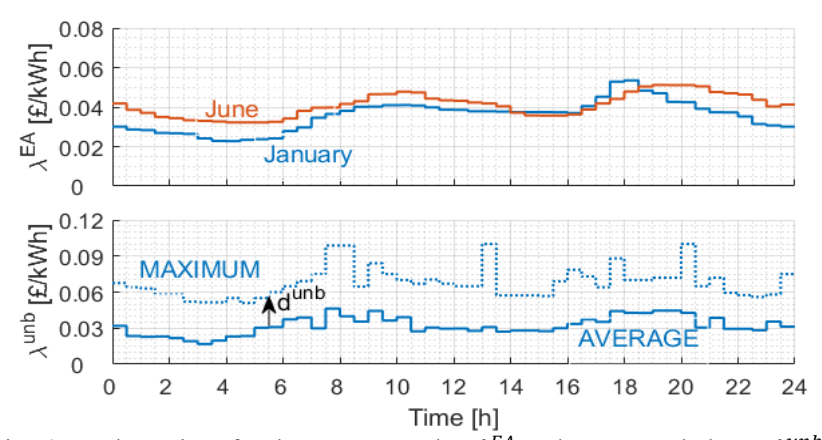

Fig. 6: Market prices for the energy market $\lambda_{k}^{E A}$ and energy unbalance $\lambda_{k}^{u n b}$.

The local network measurements (phase voltages) are sent from the RTDS to the dSpace system, together with the operating set-points defined by the $2^{\text {nd }}$ layer (energy arbitrage + regulation margins). The dSpace feeds back to the RTDS the phase currents at the at the BESS converter interface. All the commands and state feedbacks are exchanged digitally, with no need of analogue power amplifiers.

\section{B. Case study definition}

The control framework is tested under two different configurations of the set-up in Fig. 5. The first case study (CS1) assumes a purely electrical VPP, with the CHP disconnected; in the second case study (CS2), the architecture is tested under the multi-energy scenario by introducing the gas-supplied CHP. The experimental MPC settings are $\Delta T=30 \mathrm{~min}$ and $H=48$. The BESS and building parameters are listed in Table I. The PV system has a $240 \mathrm{~kW}$ rating $\left(\gamma^{p v}=240 \mathrm{~m}^{2}\right)$; a normally-distributed error $\sigma_{p}=20 \mathrm{~W} / \mathrm{m}^{2}$ is introduced to account for the mismatch between the predicted and actual irradiance. The external air temperature is $\vartheta_{a}$ is $15^{\circ} \mathrm{C}$ in the summer and $5^{\circ} \mathrm{C}$ in winter. The heat-pump parameters are $C O P_{n}^{H}=2.5$ and $C O P_{n}^{C}=1.5$, while the $C H P$ efficiencies are $\eta^{P}=0.35$ and $\eta^{Q}=0.55$. The maximum gas supply $\overline{\dot{m}}^{g a s}$ is $20 \mathrm{~m}^{3} / \mathrm{h}$. Table II lists the cost parameters. The frequency profiles have been measured at the Point of Grid Coupling (PGC) of the setup with the UK public network.

The hourly average market price for the energy arbitrage $\lambda_{k}^{E A}$, is shown in Fig. 6 (top plot) for typical summer and winter months (July 2019, January 2020). The energy price $\lambda_{k}^{E A}$ shows a clear seasonality (up to $25 \%$ difference in some hours), so two separate market scenarios are tested to evaluate the VPP performances. The unbalance fee $\lambda_{k}^{u n b}$ has a strong daily variation (its standard deviation almost equals the average value), but with little seasonality; the combined hourly average $\lambda_{k}^{u n b}$ for January-June is shown in in Fig. 6, bottom plot. The difference $d^{u n b}$ between maximum and average profiles is used in the robust approach (27).

\section{EXPERIMENTAL RESULTS: CS1}

\section{A. DH allocation, summer price scenario}

Fig. 7 and Fig. 8 show the performance of the control for the summer price data from Fig. 6, under the purely-electrical scenario of CS1. Fig. 7 shows the DH scheduler's profiles for the energy market contribution $P_{v p p D H}^{E A}$ and the frequency regulation limits $P_{v p p D H}^{F R}$, together with the price profiles $\lambda^{E A}$ and $\lambda^{F R}$. The energy arbitrage waveforms (top plot of Fig. 7) show the VPP is scheduled to absorb power from the network $\left(P_{v p p D H}^{E A}>0\right)$ whenever the energy price is a local minimum $(\mathrm{t}=4.5 \mathrm{~h}$ and $\mathrm{t}=15.5 \mathrm{~h})$, and the energy is sold back to the grid (or consumed locally) whenever the sell price is a local maximum $(\mathrm{t}=10 \mathrm{~h}$ and $\mathrm{t}=19.5 \mathrm{~h})$. The $\mathrm{DH}$ scheduler allocates the frequency regulation limits to maximize the corresponding earnings but while respecting the constraints from the energy arbitrage commitment. Whenever arbitrage operations are carried out, the scheduler reduces the allocated regulation margins $(\mathrm{t}=4.5 \mathrm{~h}, 10 \mathrm{~h}, 15.5 \mathrm{~h}, 19.5 \mathrm{~h})$.

Fig. 8 (top plot) shows the SoC profiles from the $\mathrm{DH}$ allocation; only the SoC profile based on the energy arbitrage is plotted for clarity, though in the $\mathrm{DH}$ scheduler the two SoC profiles $S_{o} C_{i}^{ \pm}$which include the effect of the frequency regulation are calculated and used. The profiles of the frequency regulation limits are also shown in Fig. 8 (middle and bottom plots). The results show that while the frequency regulation of the VPP exhibits a symmetrical behavior (Fig. 7), each asset may have unsymmetrical frequency regulation limits due to the committed power allocation for the energy arbitrage; this increased flexibility for the VPP derives from the storage model developed in Section IV-A. As an example, BESS units 1 and 3 (characterized by higher ageing costs $\lambda_{i}^{\mathrm{A} 1 / 2}$ and low regulation cost $\lambda^{\Omega}$, Table II) tend to be allocated to frequency regulation, while the opposite occurs for BESS 2, which is fully committed to arbitrage (due to the $\operatorname{high} \lambda^{\Omega}$ ). The BESS 2 regulation margins $P_{2}^{f r \pm}$ are minimised during arbitrage commitment. 


\section{B. Intra-day operations, summer price scenario}

When the VPP enters the intra-day operations, the MPC $\left(2^{\text {nd }}\right.$ layer) updates the optimal local trajectory of the system every $\Delta T$, to minimise the error between the actual $P_{v p p}^{E A}+P_{v p p}^{F R}$ and day-ahead $P_{v p p D H}^{E A}+P_{v p p D H}^{F R}$. Fig. 9 (top plot) shows both the total expected profile of the VPP for the summer pricing profile in Fig. 6 (obtained from $P_{v p p D H}^{E A}$ and $P_{v p p D H}^{F R}$ ) and the actual power profile $\left(P_{v p p}^{E A}\right.$ plus the regulation contribution proportional to $P_{v p p}^{F R}$ ). The step changes in Fig. 9 are due to the energy arbitrage commitment and follow the scheduled arbitrage DH profile in Fig. 7 (top), while the fast-changing spikes are due to the VPP response to the frequency regulation. The correlation between the DH scheduled VPP power profile, and the VPP's actual power profile is excellent. The Mean Absolute Error (MAE) between the expected and actual power profile in Fig. 9 is $15 \mathrm{~kW}, 2.3 \%$ of the total nominal power $(640 \mathrm{~kW})$ of the VPP. According to the MPC model, the VPP always ensures the committed frequency regulation contribution, at the expense of sometimes under-delivering on the energy arbitrage commitment (e.g. $10.8 \mathrm{~h}$ in Fig. 9), and incurs the corresponding fees on the unbalance market.

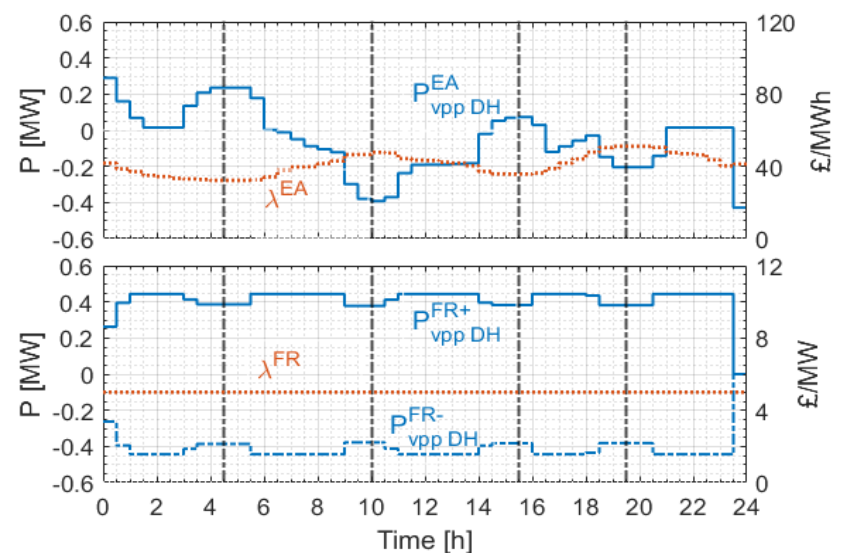

Fig. 7: Scheduled day-ahead (DH) VPP profiles for the energy market $P_{v p p D H}^{E A}$ and frequency regulation $P_{v p p D H}^{F R}$, with associated prices $\lambda^{E A} / \lambda^{F R}$

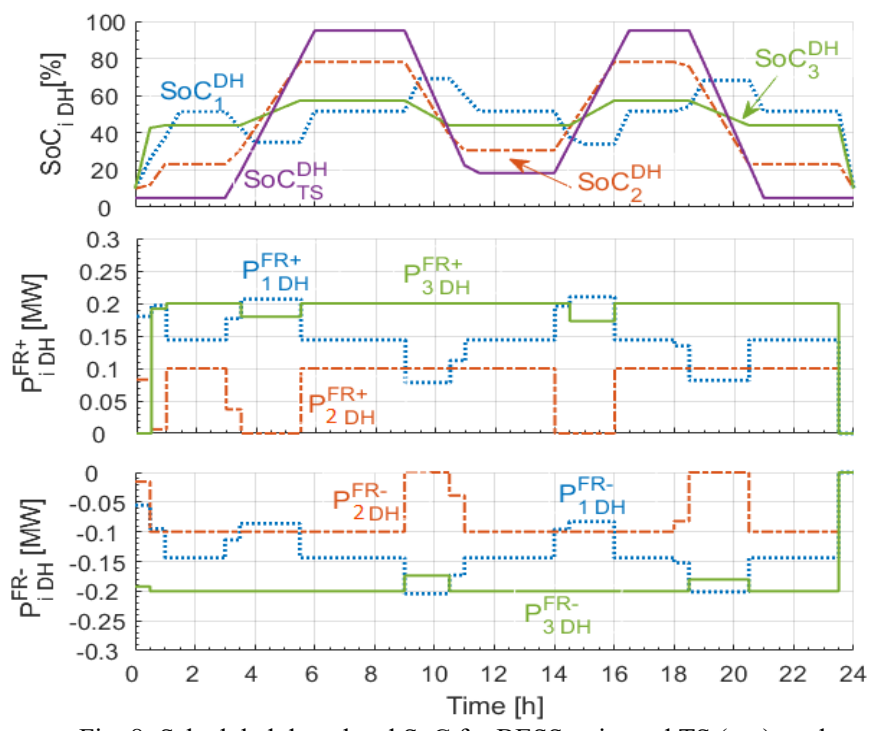

Fig. 8: Scheduled day-ahead SoC for BESS units and TS (top), and allocated frequency regulation limits $P_{i}^{f r+}$ and $P_{i}^{f r-}$ (middle and bottom).
The bottom plot in Fig. 9 shows the actual SoC profiles of the BESS units and TS. The unpredictable energy usage due to the frequency regulation results in a local deviation between the theoretical $\mathrm{DH}$ profiles and the actual SoC profiles (Fig. 9), however, the MPC reallocates the VPP assets to enable the most profitable operation of the assets and guarantee the maximum possible adherence of the profiles to the scheduled ones. It is seen how the SoC for each asset remains close to the expected $\mathrm{DH}$ one (both the energyintensive BESS 2 / TS and the more regulation-suitable units BESS 1 / BESS 3); the SoC operation limits are correctly met.

Fig. 10 shows the temperature profiles as measured in each of the building thermal zones. It can be observed that the intra-day $2^{\text {nd }}$ layer MPC maintains the temperatures within the predefined comfort limits, irrespective of the timevarying conditions associated to the external disturbances (irradiance and zone occupancy).
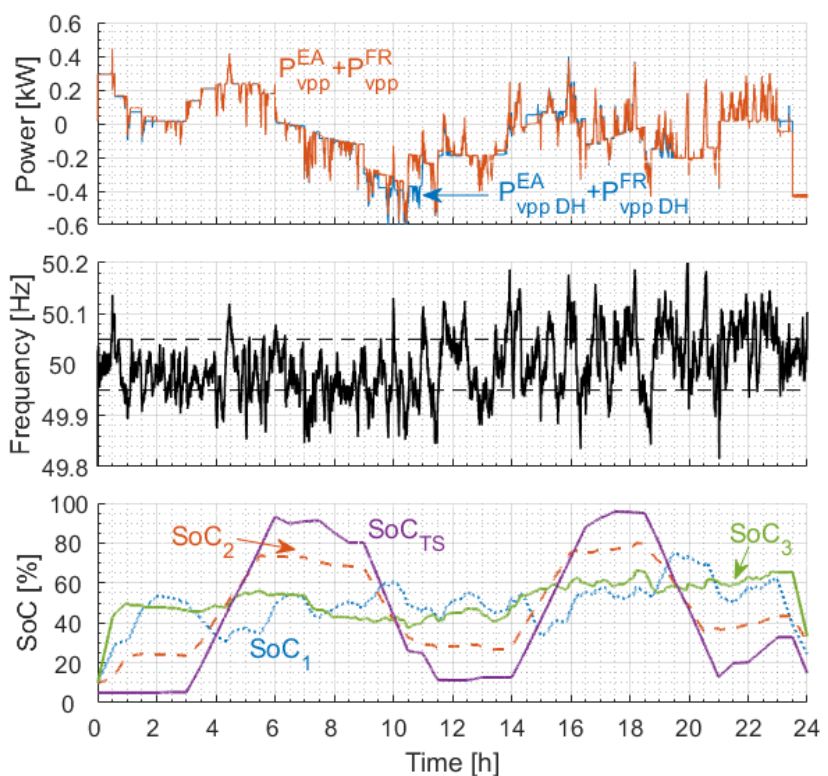

Fig. 9: Day-ahead VPP profile and actual VPP power output (top), 24 hour frequency profile (middle), and VPP assets SoC (bottom).

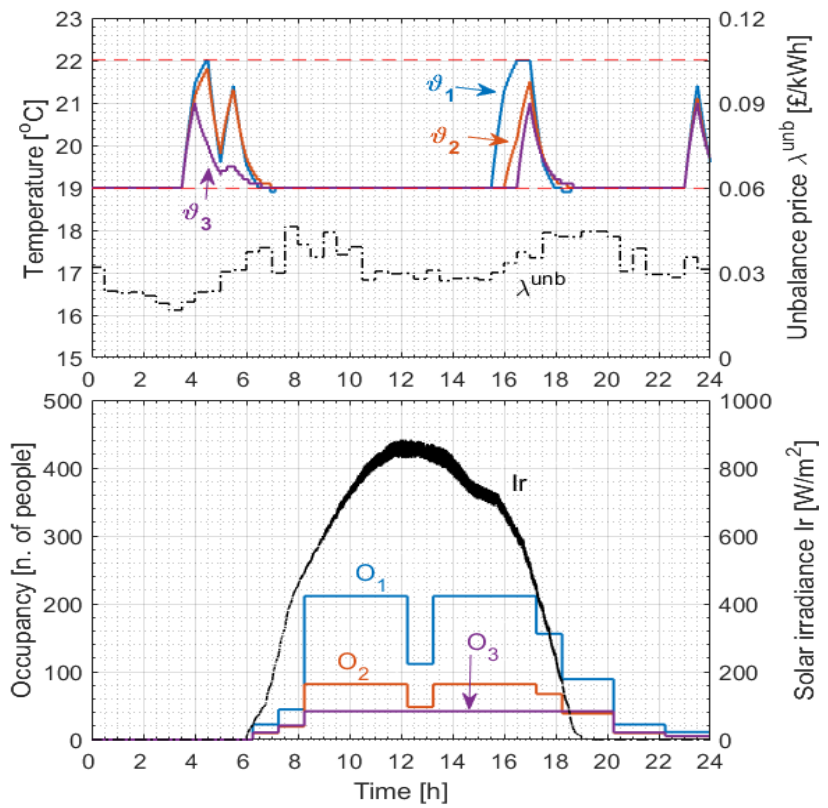

Fig. 10: Thermal zones temperature profiles and unbalance price $\lambda^{u n b}$. The irradiance and occupancies are reported in the bottom plot. 
TABle III: Daily ReVEnUE EVAluation (WINTER / SUMMER): CASE STUDY 1

\begin{tabular}{|c|c|c|c|c|c|}
\hline \multicolumn{2}{|c|}{ Case } & \multicolumn{3}{|c|}{ VPP (storage + TS + building + PV) } & PV and building only \\
\hline $\begin{array}{l}\text { Day-al } \\
\text { Markets }\end{array}$ & $\begin{array}{l}\mathrm{ad} \\
\text { day) }\end{array}$ & $\begin{array}{c}\text { Energy Arbitrage }(\mathrm{W} ; \mathrm{S}) \\
2.50 ; 79.34\end{array}$ & $\begin{array}{l}\text { Frequency reg. }(\mathrm{W} ; \mathrm{S}) \\
28.23 ; 108.52 £\end{array}$ & $\begin{array}{c}\text { Stacked services }(\mathrm{W} ; \mathrm{S}) \\
37.37 ; 114.19\end{array}$ & $\begin{array}{l}\text { Building-control only }(\mathrm{W} ; \mathrm{S}) \\
-20.65 ; 59.64\end{array}$ \\
\hline $\begin{array}{l}\text { Unbalance } \\
\text { fees } \\
\text { (£/day) }\end{array}$ & $\begin{array}{l}\Gamma=0 \\
\Gamma=1 \\
\Gamma=2 \\
\Gamma=3\end{array}$ & $\begin{array}{l}-2.49 ;-2.21 \\
-2.50 ;-2.38 \\
-2.36 ;-2.34 \\
-2.72 ;-2.32\end{array}$ & $\begin{array}{l}-5.18 ;-5.93 \\
-5.05 ;-5.36 \\
-5.03 ;-6.09 \\
-6.12 ;-6.77\end{array}$ & $\begin{array}{l}-4.17 ;-4.68 \\
-4.13 ;-4.09 \\
-4.03 ;-4.01 \\
-4.26 ;-4.10\end{array}$ & $\begin{array}{l}-0.59 ;-1.1 \\
-0.63 ;-1.2 \\
-0.48 ;-1.2 \\
-0.65 ;-1.3\end{array}$ \\
\hline Total revenu & $($ best $\Gamma)$ & $£ 0.14 ; £ 77.13$ & $£ 23.22 ; £ 103.16$ & $£ 33.34 ; £ 110.18$ & $£-21.13 ; £ 58.54$ \\
\hline Mean & $\Gamma=0$ & $14.02 \mathrm{~kW} ; 14.23 \mathrm{~kW}$ & $18.55 \mathrm{~kW} ; 19.79 \mathrm{~kW}$ & $15.13 \mathrm{~kW} ; 15.10 \mathrm{~kW}$ & $2.75 \mathrm{~kW} ; 2.84 \mathrm{~kW}$ \\
\hline Absolute & $\Gamma=1$ & $13.98 \mathrm{~kW} ; 14.84 \mathrm{~kW}$ & $18.01 \mathrm{~kW} ; 16.63 \mathrm{~kW}$ & $14.01 \mathrm{~kW} ; 13.89 \mathrm{~kW}$ & $2.19 \mathrm{~kW} ; 2.61 \mathrm{~kW}$ \\
\hline $\begin{array}{l}\text { Error MAE } \\
\quad(\mathrm{kW})\end{array}$ & $\begin{array}{l}\Gamma=2 \\
\Gamma=3\end{array}$ & $\begin{array}{l}13.96 \mathrm{~kW} ; 14.40 \mathrm{~kW} \\
13.95 \mathrm{~kW}: 14.14 \mathrm{~kW}\end{array}$ & $\begin{array}{l}17.45 \mathrm{~kW} ; 18.52 \mathrm{~kW} \\
18.99 \mathrm{~kW}: 19.01 \mathrm{~kW}\end{array}$ & $\begin{array}{l}13.85 \mathrm{~kW} ; 13.18 \mathrm{~kW} \\
1446 \mathrm{~kW} \cdot 1448 \mathrm{~kW}\end{array}$ & $\begin{array}{l}2.56 \mathrm{~kW} ; 2.62 \mathrm{~kW} \\
2.63 \mathrm{~kW} \cdot 2.60 \mathrm{~kW}\end{array}$ \\
\hline
\end{tabular}

The proposed approach allows to take advantage of the thermal inertia of the building, rising the temperature of the controlled zones before a forecasted increase of the unbalance fees. This way the potentially negative impact of an unpredicted energy absorption in correspondence to the price peak is minimized.

The computational time for the $3^{\text {rd }}$ layer optimal solution (day-ahead) is in the order of a couple of minutes, and between 65 and 95 seconds for the $2^{\text {nd }}$ layer (intra-day) on a 64-bits Intel ${ }^{\circledR}$ Core $^{\mathrm{TM}}$ i7-6700 CPU $3.40 \mathrm{GHz}$ processor with 16.0 GB RAM. Nevertheless, the time can be significantly reduced (up to 20 seconds for the $2^{\text {nd }}$ layer) exploiting the CPLEX model pre-compilation. This allows to potentially accommodate a larger number of assets or to reduce the optimization time step $\Delta T$ for improved performance.

\section{Results: revenues evaluation (case study 1)}

Table III shows the revenue for the stacking mechanism compared to the single-service ones (Energy Arbitrage and Frequency Regulation), under the winter (W) and summer (S) price scenarios. A simple case showing just the net contribution from the PV and building is also included in the $4^{\text {th }}$ column to assess the impact of the different assets. The sum of the day-ahead and unbalance markets (with different robustness factors $\Gamma$ ) defines the total VPP revenue.

In all scenarios, the stacked operations ( $3^{\text {rd }}$ column) outperforms the single-service ones, yielding a revenue increase of $+30 \%$ (winter) and $+7 \%$ (summer) when compared to frequency regulation only, and up to $+99 \%$ (winter) and $+30 \%$ (summer) compared to the energy arbitrage alone. Non-null factors $\Gamma$ typically yield higher revenues, confirming the unbalance fees robust optimization model correctness (Section V). The low MAEs of the actual profiles against the allocated $3^{\text {rd }}$ layer ones confirm the consistency of the proposed approach.

\section{EXPERIMENTAL RESULTS: CS2}

The case study CS2 assesses the proposed approach under the multi-energy scenario (electricity + gas). Fig. 11 shows the theoretical energy arbitrage $P_{v p p D H}^{E A}$, frequency regulation margins $P_{v p p D H}^{F R \pm}$ and the gas supply $\dot{m}_{D H}^{g a s}$ profiles from the $3^{\text {rd }}$ layer, together with the actual ones during real-time operations. The algorithm allocates the gas absorption in correspondence to the electrical energy price peaks, taking advantage of the price differences between the energy vectors (highlighted areas in Fig. 11). During intra-day conditions, the energy arbitrage profile (top subplot) accurately follows the scheduled DH one, with just small mismatches due to the uncertainty of the physical operations (e.g. $\mathrm{t}=10 \mathrm{~h}$ ). As the same time, the instantaneous frequency regulation $P_{v p p}^{F R}(f)$ (middle plot, Fig. 11) is correctly contained within the allocated margins $P_{v p p D H}^{F R \pm}$. The gas supply almost-perfectly follows the expected $\mathrm{DH}$ profile. These results demonstrate the proposed approach effectiveness in compensating for the uncertainty of the real-time conditions.

To further assess the control robustness against the price uncertainty, an extensive sensitivity analysis is performed (Fig.12). The goal is to show that, irrespective of the chosen values of the regulation $\lambda^{F R}$ and gas-supply prices $\lambda^{G A S}$, the stacking architecture outperforms the simple energy arbitrage (solid lines) and the frequency regulation (dash-dot lines) operations: this can be observed from the always-positive revenues increase of the stacked model with respect to the single-service approaches (Fig.12), confirming the increased performances of the proposed control approach.
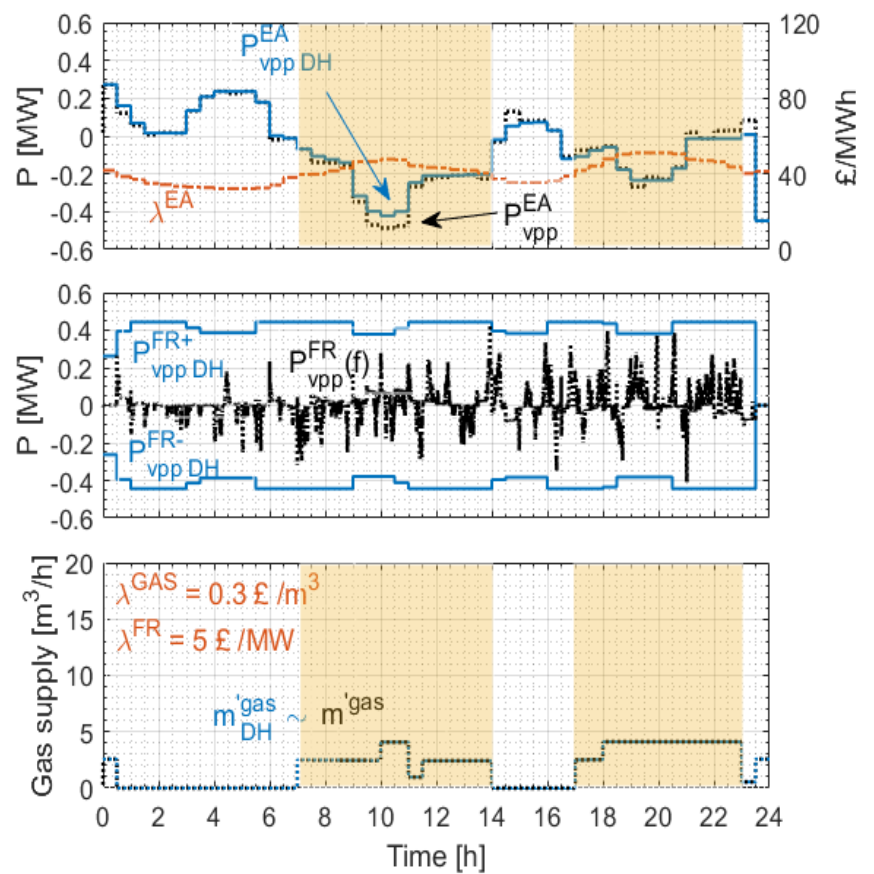

Fig. 11: Scheduled day-ahead and real-time VPP power profiles for the energy market $P_{v p p D H}^{E A}$ (on top), frequency regulation $P_{v p p D H}^{F R}$ (middle) and the gas supply (bottom) under the multi-energy scenario CS2. 


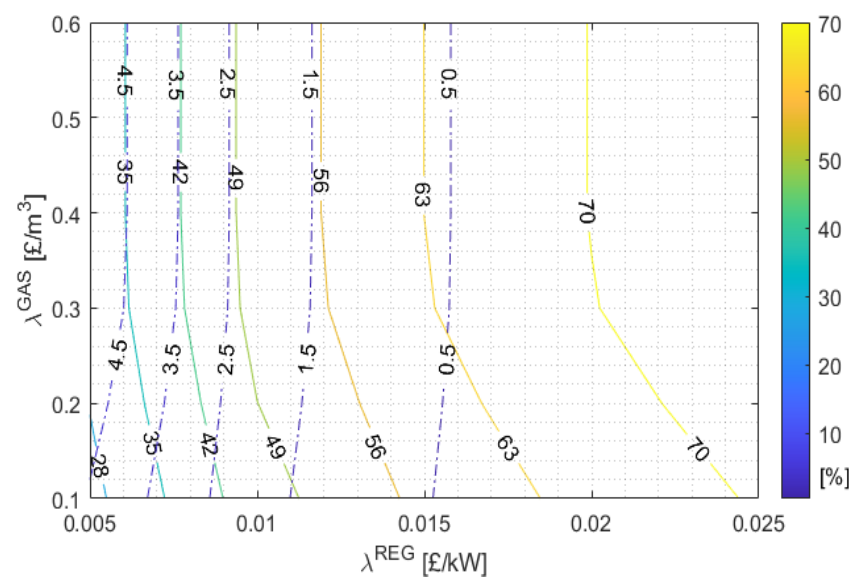

Fig. 12: Revenues increase of the stacked operations against Energy Arbitrage (solid lines) and Frequency regulation (dash-dot lines) in CS2.

\section{CONCLUSION}

A hierarchical control architecture has been proposed and validated experimentally to enable the optimal grid support service commitment of a virtual power plant (VPP), maximizing net revenue. The day-ahead optimization considers market prices for the different grid support services, together with battery ageing costs. The intermediate control layer regulates the intra-day operation of the VPP using a MPC technique to minimize the penalties for failing to deliver the committed services, and the low-level control regulates the assets to perform grid frequency support. Two case studies are tested, one purely electrical, and the second multienergy. The results show the superiority of the multipleservice operation compared to providing a single grid support service. For example, the net revenue is increased by $30 \%$ (winter) and 7\% (summer) when compared to just frequency regulation, and by $+99 \%$ (winter) and $30 \%$ (summer) when compared to only energy arbitrage. Similar results are obtained in the multi-energy scenario under an extensive price sensitivity analysis, confirming the effectiveness of the approach over a broad range of operating conditions.

Although several optimization models are available in the literature, the proposed experimental extension provides a significant result, in particular by including the real-time optimization. Future studies will analyze the model extension to the non-linear case under the simultaneous provision of active / reactive services and advanced handling of the uncertainty through the affine disturbance feedback technique.

\section{APPENDIX: BESS MILP MODEL}

The logical condition in (3) in the BESS dynamics is modelled in a MILP form to obtain a tractable optimization problem. Although based on a general technique in [28], its application to the stacking services and the derived equations are unpublished, to the best of the authors' knowledge. A binary variable $\delta_{i}^{e a}(k) \in\{0,1\}$ (28) is introduced $\forall i \in$ $1 \ldots N^{s t}$ to model the discontinuous behavior of the efficiency expressed in (3). Following the procedure in [28], the nonlinear logical condition (28) can be expressed in inequality form by (29), where a small tolerance $\varepsilon$ guarantees non-strict inequalities in the resulting problem.

$$
\left\{\begin{array}{c}
P_{i}^{e a}(k) \geq 0 \leftrightarrow \delta_{i}^{e a}(k)=1 \\
P_{i}^{e a}(k) \in\left[\underline{P_{i}^{*}} ; \overline{P_{i}^{*}}\right]
\end{array}\right.
$$

where $P_{i}^{*}=P_{i}-P_{i}^{f r-}(k), \overline{P_{i}^{*}}=\overline{P_{i}}-P_{i}^{f r+}(k)$.

$$
\left\{\begin{array}{c}
P_{i}^{e a}(k)-\left(\overline{P_{i}^{*}}+\varepsilon\right) \delta_{i}^{e a}(k)+\varepsilon \leq 0 \\
-P_{i}^{e a}(k)+P_{i}^{*}\left(1-\delta_{i}^{e a}(k)\right) \leq 0
\end{array}\right.
$$

Substituting (2) into (4)-(5) and introducing the $\delta_{i}^{e a}(k)$ definition (28), gives (30)-(31),

$$
\begin{gathered}
\operatorname{SoC}_{i}^{+}(k+1)=\operatorname{So} C_{i}(k)+\frac{\eta_{i}^{c h} \Delta T}{E_{i}} P_{i}^{f r+}(k)+m \\
\operatorname{SoC}_{i}^{-}(k+1)=\operatorname{So} C_{i}(k)+\frac{\Delta T}{E_{i} \eta_{i}^{d i s}} P_{i}^{f r-}(k)+m \\
\text { where } m=\frac{\Delta T P_{i}^{e a}(k)}{E_{i}}\left[\eta_{i}^{c h} \delta_{i}^{e a}(k)+\frac{1}{\eta_{i}^{d i s}}\left(1-\delta_{i}^{e a}(k)\right)\right] .
\end{gathered}
$$

Due to the products between real and binary variables in (30)-(31), three auxiliary quantities (32) are introduced to maintain a linear formulation: each auxiliary variable in (32) is defined by a system of four linear inequalities (33).

$$
\begin{aligned}
& \left\{\begin{array}{l}
z_{i}^{e a}(k)=\delta_{i}^{e a}(k) P_{i}^{e a}(k), P_{i}^{e a}(k) \in\left[\underline{P_{i}^{*}} ; \overline{P_{i}^{*}}\right] \\
z_{i}^{f r+}(k)=\delta_{i}^{e a}(k) P_{i}^{f r+}(k), P_{i}^{f r+}(k) \in\left[0 ; \overline{P_{i}^{f r}}\right] \\
z_{i}^{f r-}(k)=\delta_{i}^{e a}(k) P_{i}^{f r-}(k), P_{i}^{f r-}(k) \in\left[P_{i}^{f r} ; 0\right]
\end{array}\right. \\
& L(k):=\left\{P_{i}^{e a}(k), P_{i}^{f r+}(k), P_{i}^{f r-}(k)\right\}, \delta^{e a}(k):\{0,1\} \\
& \forall \mathrm{y} \in L(k), y \leq y \leq \bar{y}: \quad z_{y}(k)=y(k) \delta^{e a}(k) \\
& \left\{\begin{array}{c}
z_{y}(k)-\bar{y} \delta^{e a}(k) \leq 0 \\
-z_{y}(k)+\underline{y} \delta^{e a}(k) \leq 0 \\
z_{y}(k)-y(k)+\underline{y}\left(1-\delta^{e a}(k)\right) \leq 0 \\
-z_{y}(k)+y(k)-\bar{y}\left(1-\delta^{e a}(k)\right) \leq 0
\end{array}\right.
\end{aligned}
$$

The MILP BESS model is thus given by the vector inequality (34) in the decision $S o C_{i}^{ \pm}, P_{i}^{e a}, P_{i}^{f r \pm}$ and auxiliary $z_{i}^{f r \pm}$, $z_{i}^{e a}, \delta_{i}^{e a}$ variables, plus the linear forms of (30)-(31).

$$
\begin{aligned}
& \boldsymbol{M}_{\boldsymbol{P}}^{e \boldsymbol{a}} P_{i}^{e a}+\boldsymbol{M}_{\boldsymbol{P}}^{f r+} P_{i}^{f r+}+\boldsymbol{M}_{\boldsymbol{P}}^{\boldsymbol{f r}-} P_{i}^{f r-}+\boldsymbol{M}_{\boldsymbol{\delta}}^{\boldsymbol{e a}} \delta_{i}^{e a}+\boldsymbol{M}_{\mathbf{z}}^{e \boldsymbol{a}} z_{i}^{e a}+ \\
& +\boldsymbol{M}_{\mathrm{z}}^{\mathrm{fr}+} z_{i}^{f r+}+\boldsymbol{M}_{\mathrm{z}}^{\mathrm{fr}-} z_{i}^{f r-}+\boldsymbol{M}_{\mathrm{So} \boldsymbol{C}}^{+} \mathrm{SoC}_{i}^{+}+\boldsymbol{M}_{\text {SoC }}^{-} \mathrm{SoC}_{i}^{-} \leq \boldsymbol{M}_{t}
\end{aligned}
$$

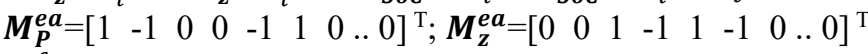

$$
\begin{aligned}
& \boldsymbol{M}_{\boldsymbol{P}}^{\boldsymbol{f r +}}=\left[\begin{array}{llllllllllllllll}
0 & 0 & 0 & 0 & 0 & 1 & 0 & 0 & -1 & 1 & 0 & 0 & 0 & 0 & 0 & 0
\end{array}\right]^{\mathrm{T}} \\
& \boldsymbol{M}_{\boldsymbol{P}}^{\boldsymbol{f r}-\boldsymbol{r}}=\left[\begin{array}{llllllllllllllll}
0 & -1 & 0 & 0 & -1 & 0 & 0 & 0 & 0 & 0 & 0 & 0 & -1 & 1 & 0 & 0
\end{array}\right]^{\mathrm{T}} \\
& \boldsymbol{M}_{\boldsymbol{\delta}}^{\boldsymbol{e a}}=\left[-\left(\overline{P_{i}}+\varepsilon\right)-\underline{P_{i}}-\overline{P_{i}} \underline{P_{i}}-\underline{-P_{i}} \overline{P_{i}}-\overline{P_{i}^{f r}} 00 \overline{P_{i}^{f r}}\right. \\
& \left.0 P_{i}^{f r}-P_{i}^{f \bar{r}} 0000\right]^{\mathrm{T}} \\
& \boldsymbol{M}_{\mathbf{z}}^{\boldsymbol{f r +}}=\left[\begin{array}{llllllllllllllll}
1 & 0 & 1 & 0 & 0 & -1 & 1 & -1 & 1 & -1 & 0 & 0 & 0 & 0 & 0 & 0
\end{array}\right]^{\mathrm{T}} \\
& \boldsymbol{M}_{\boldsymbol{z}}^{\boldsymbol{f r}-\boldsymbol{r}}=\left[\begin{array}{llllllllllllllll}
0 & 1 & 0 & -1 & 1 & 0 & 0 & 0 & 0 & 0 & 1 & -1 & 1 & -1 & 0 & 0
\end{array}\right]^{\mathrm{T}} \\
& \boldsymbol{M}_{\text {SoC }}^{+}=\left[\begin{array}{lllll}
0 & \ldots & 0 & 1 & 0
\end{array}\right]^{\mathrm{T}} ; \quad \boldsymbol{M}_{\boldsymbol{S o C}}^{-}=\left[\begin{array}{lllll}
0 & \ldots & 0 & 0 & -1
\end{array}\right]^{\mathrm{T}}
\end{aligned}
$$

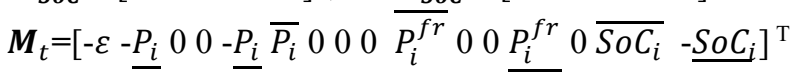

\section{REFERENCES}

[1] L. Yavuz, A. Önen, S. M. Muyeen, and I. Kamwa, "Transformation of microgrid to virtual power plant - A comprehensive review," IET Gener. Transm. Distrib., vol. 13, no. 11, pp. 2077-2087, 2019.

[2] A. Parisio, E. Rikos, and L. Glielmo, "A Model Predictive Control Approach to Microgrid Operation Optimization," IEEE Trans. Control Syst. Technol., vol. 22, no. 5, pp. 1813-1827, Sep. 2014. 
[3] G. Mantovani et al., "Experimental Validation of Energy Resources Integration in Microgrids via Distributed Predictive Control," IEEE Trans. Energy Convers., vol. 29, no. 4, pp. 1018-1025, Dec. 2014.

[4] B. Zhou, X. Liu, Y. Cao, C. Li, C. Y. Chung, and K. W. Chan, "Optimal scheduling of virtual power plant with battery degradation cost," IET Gener. Transm. Distrib., vol. 10, no. 3, pp. 712-725, 2016.

[5] J. Kim et al., "Capability-coordinated frequency control scheme of a virtual power plant with renewable energy sources," IET Gener. Transm. Distrib., vol. 13, no. 16, pp. 3642-3648, 2019.

[6] D. Zhao, H. Wang, J. Huang, and X. Lin, "Virtual Energy Storage Sharing and Capacity Allocation," IEEE Trans. Smart Grid, vol. 11, no. 2, pp. 1112-1123, 2020.

[7] X. Zhu, J. Yang, Y. Liu, C. Liu, B. Miao, L. Chen, “Optimal scheduling method for a regional integrated energy system considering joint virtual energy storage," IEEE Access, vol. 7, pp. 138260-138272, 2019.

[8] B. M. Gundogdu, D. T. Gladwin, S. Nejad, and D. A. Stone, "Scheduling of grid-tied battery energy storage system participating in frequency response services and energy arbitrage," IET Gener. Transm. Distrib., vol. 13, no. 14, pp. 2930-2941, 2019.

[9] G. He, Q. Chen, C. Kang, Q. Xia, and K. Poolla, "Cooperation of Wind Power and Battery Storage to Provide Frequency Regulation in Power Markets," IEEE Trans. Power Syst., vol. 32, no. 5, pp. 3559-3568, 2017.

[10]T. Zhang, S. X. Chen, H. B. Gooi, J. M. Maciejowski, "A hierarchical EMS for aggregated BESSs in energy and performance-based regulation markets," IEEE Trans. Power Syst., vol. 32, no. 3, pp. 1751-1760, 2017.

[11]A. Perez, R. Moreno, R. Moreira, M. Orchard, and G. Strbac, "Effect of Battery Degradation on Multi-Service Portfolios of Energy Storage," IEEE Trans. Sustain. Energy, vol. 7, no. 4, pp. 1718-1729, 2016.

[12]A. Baringo, L. Baringo, J. M. Arroyo, "Day-Ahead Self-Scheduling of Virtual Power Plant in Energy and Reserve Markets under Uncertainty," IEEE Trans. Power Syst., vol.34, no.3, pp. 1881-1894, 2019.

[13]R. T. Elliott et al., "Sharing Energy Storage Between Transmission and Distribution," IEEE Trans. Power Syst. vol. 34, no. 1, pp.152-162, 2019

[14]A. La Bella, S. Raimondi Cominesi, C. Sandroni, and R. Scattolini, "Hierarchical Predictive Control of Microgrids in Islanded Operation," IEEE Trans. Autom. Sci. Eng., vol. 14, no. 2, pp. 536-546, Apr. 2017.

[15]D. Bertsimas and M. Sim, "Robust discrete optimization and network flows," Math. Program., vol. 98, no. 1-3, pp. 49-71, 2003.

[16] A. Bitlislioğlu, T. T. Gorecki and C. N. Jones, "Robust Tracking Commitment," in IEEE Trans. on Automatic Control, vol. 62, no. 9, pp 4451-4466, Sept. 2017.

[17]A. Bolzoni, Q. Zhu, V. Tsormpatzoudis, R. Todd, A.J. Forsyth, "Dynamical Characterization of Grid-Scale Energy Storage Assets,", $42^{\text {nd }}$ Ind. Electr. Conf. IECON 2019, pp.1-8. 2019.

[18]National Grid, "Testing guidance for providers of enhanced frequency response balance service", 2017. Online at:

https://www.nationalgrid.com/sites/default/files/documents/ EFR\%20Testing\%20Guidance\%20VD3\%20\%28Final\%29.pdf

[19] Terna, "Technical requirements for Fast Reserve Units," 2020. Online: https://download.terna.it/terna/FastReserve_Allegato\%203_Tecnico_ 8d76dc04c201b52.pdf

[20] R. Rosso, S. Engelken, M. Liserre, "Robust Stability Investigation of the Interactions among Grid-Forming and Grid-Following Converters,' IEEE J. Emerg. Sel. Top. Pow. Elect., vol. 8, no. 2, pp. 991-1003, 2020.

[21]A. Bolzoni, R. Perini, "Experimental validation of novel angular estimator for synthetic inertia support under disturbed network conditions," 2019, 21 $1^{\text {st }}$ Eur. Conf. Pow. Elec.Appl. EPE-ECCE, pp.1-10.

[22]E. Ogliari, A. Bolzoni, S. Leva, and M. Mussetta, "Day-ahead PV Power Forecast by Hybrid ANN Compared to the Five Parameters Model Estimated by Particle Filter Algorithm," in Lecture Notes in Computer Science, vol. 9887 LNCS, 2016, pp. 291-298.

[23] A. Parisio and S. P. Gutierrez, "Distributed model predictive control for building demand-side management," 2018 Eur. Control Conf. ECC 2018, pp. 2549-2554, 2018

[24]J. M. Reniers, G. Mulder, S. Ober-Blöbaum, and D. A. Howey, "Improving optimal control of grid-connected lithium-ion batteries through more accurate battery and degradation modelling," J. Power Sources, vol. 379, pp. 91-102, Mar. 2018.

[25]L. Meng et al., "Fast Frequency Response From Energy Storage Systems - A Review of Grid Standards, Projects and Technical Issues,' IEEE Trans. Smart Grid, vol. 11, no. 2, pp. 1566-1581, Mar. 2020

[26]NORD POOL, "Energy market prices". Online: https://www.nordpoolgroup.com/Market-data1/GB/Auction-prices/UK.

[27]ELEXON, "Balancing market prices". Online: https://www.bmreports.com/bmrs/.

[28]H. P. Williams, Model Building in Mathematical Programming, 5th ed. Wiley and Sons, 2013.

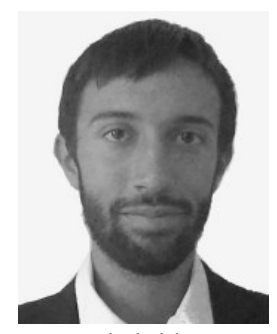

Alberto Bolzoni (Member, IEEE) received his $\mathrm{MS}$ and $\mathrm{PhD}$ degrees in electrical engineering at Politecnico di Milano, Milano, Italy, in 2015 and in 2019 respectively. Since 2019 he has been a post-doctoral research associate in the Electrica and Electronic Engineering Department at The University of Manchester, UK. His main field of interest is control theory applied to power electronics, with a particular focus on gridconnected converters, battery energy storage systems, hybrid power plants and microgrids.

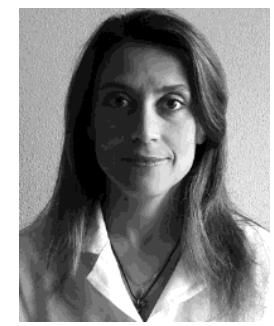

Alessandra Parisio (Senior Member, IEEE) received the $\mathrm{Ph} . \mathrm{D}$. degree in automatic contro from the University of Sannio, Benevento, Italy. As a visiting Ph.D. student, she spent one year with the Swiss Federal Institute of Technology. She was a Postdoctoral Research Fellow with the Automatic Control Laboratory, Royal Institute of Technology, Sweden. She is currently a Senior Lecturer in Electrical and Electronic Engineering with the Faculty of Science and Engineering, University of Manchester, Manchester, U.K. She is the Vice-Chair of the IFAC Technical Committee 9.3. Control for Smart Cities and an Editor for the Elsevier journal Sustainable Energy, Grids and Networks. Her research interests include the areas of large-scale control and optimization of energy systems and stochastic constrained control.

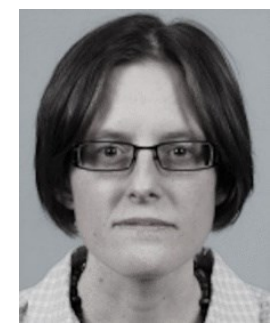

Rebecca Todd (Senior Member, IEEE) received the M.Eng. degree in electrical engineering from The University of Manchester Institute of Science and Technology, Manchester, U.K., in 2001 and the Eng.D. degree in electrical machine control from The University of Manchester in 2006. From 2010 to 2020, she was a Lecturer and Senior Lecturer with The University of Manchester. Her research interests included advanced control methods for energy storage systems in transmission and distribution networks, hybrid power plants, and power electronic converter design for aerospace systems and electric vehicles.

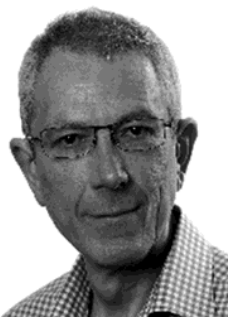

Andrew J. Forsyth (Senior Member, IEEE) received the B.Sc.(Eng.) degree in electrical engineering from Imperial College, London, U.K., in 1981, and the Ph.D. degree in power electronics from the University of Cambridge Cambridge, U.K., in 1987. He was a Design Engineer with GEC Electrical Projects, Ltd., from 1981 to 1983, a Lecturer with the University of Bath from 1986 to 1990 , and a Lecturer/Senior Lecturer with Birmingham University from 1991 to 2004. Since 2004, he has been a Professor of power electronics with the University of Manchester, Manchester, U.K. His research interests include high-frequency converters and magnetic components, converter modeling and control, and aerospace and electric vehicle applications. 